\title{
FORMULATION AND EVALUATION OF IBUPROFEN CONTROLLED RELEASE MATRIX TABLETS USING ITS SOLID DISPERSION
}

\section{SREEJAN MANNA ${ }^{1 *}$, JYOSHNA KOLLABATHULA ${ }^{2}$}

1Department of Pharmaceutical Technology, Brainware University, Barasat, Kolkata, West Bengal 700125, India, ${ }^{2}$ Department of Pharmaceutical Analysis, Chalapathi Institute of Pharmaceutical Sciences, Chalapathi Nagar, LAM, Guntur, Andhra Pradesh 522034, India Email: manna. sreejan@gmail.com

Received: 27 Oct 2018, Revised and Accepted: 09 Jan 2019

\section{ABSTRACT}

Objective: The aim of the present work was to prepare solid dispersion of ibuprofen with PEG 6000 to increase the aqueous solubility of the drug and to develop the solid dispersed ibuprofen into tablet formulation with the combination of a hydrophilic and hydrophobic polymer to attain controlled release of ibuprofen.

Methods: Solid dispersion of ibuprofen was prepared by melting-solvent method by varying the ratio of drug and PEG 6000. The solid dispersed ibuprofen was subjected to tablet formulation by using a hydrophilic swellable polymer-carbopol and hydrophobic non-swellable polymer-ethyl cellulose. The release of the drug from the polymer matrix was studied as the polymer ratio changes.

Results: Compatibility between drug and polymers was established from FT-IR study. The saturated solubility was found to increase in the solid dispersed formulation. The swelling index was found within the range of $90 \pm 5.43$ to $137 \pm 6.41$. SEM image of swollen tablet confirmed the presence of irregular and porous surface. The cumulative drug release was found to vary within the range of $68.76 \pm 3.04$ to $95.33 \pm 2.34 \%$ after $8 \mathrm{~h}$ of dissolution.

Conclusion: The combination of solid dispersion and application of hydrophilic and hydrophobic polymers in matrix formation can facilitate better dissolution and absorption profile with greater patient compliance.

Keywords: Ibuprofen, Solid dispersion, PEG 6000, Carbopol, Ethylcellulose

(C) 2019 The Authors. Published by Innovare Academic Sciences Pvt Ltd. This is an open access article under the CC BY license (http://creativecommons.org/licenses/by/4.0/) DOI: http://dx.doi.org/10.22159/ijap.2019v11i2.30503

\section{INTRODUCTION}

Orally administered drugs go through dissolution and then permeate across the epithelial membrane before appearing in the systemic circulation. Apart from solubility and permeability, the dissolution rate of the drug is one of the major factors for the bioavailability of the drug. Solubility of the drug in the gastro-intestinal medium is a major concern for most of the drugs [1]. Around $40 \%$ of the new drug substances are having poor aqueous solubility. This leads to reduced bioavailability and possible adverse effects [2]. Thus solubility of new drug substances is the biggest challenge to formulation scientists $[3,4]$. In spite of these challenges, oral route has been predominantly preferred route for drug administration due to its easy administration, high patient compliance and flexibility in dosage form design $[3,5]$.

Ibuprofen, a non-steroidal anti-inflammatory drug (NSAID) widely used to reduce pain, tenderness, inflammation, and stiffness caused by gout and arthritis [6]. It is also used in the therapy of muscle ache, fever, menstrual pain and post-surgical pain [7]. Ibuprofen is a nonselective inhibitor of cyclooxygenase (COX) which inhibits two isoform of cyclooxygenase, COX-1, and COX-2 [8]. The inhibition of COX-1 is responsible for unwanted effects on GI tract and platelet aggregation, whereas COX-2 is responsible for the analgesic, antipyretic, and antiinflammatory activity of NSAIDs $[9,10]$. However, the function of each isoform of COX on analgesic, antipyretic, anti-inflammatory activity, and the severity of gastric damage of NSAIDs is uncertain and different compounds can cause different degrees of physiological effects and gastric damage $[11,12]$.

Solid dispersions can be defined as a dispersion of one or more active ingredients in an inert carrier or matrix in the solid state prepared by co-melting or solvent extraction or by the solventmelt method [13]. Solid dispersion drug formulation represents an excellent method to enhance the solubility of poorly water-soluble drugs, as well as for the reduction of the ulcerogenic effect of nonsteroidal anti-inflammatory drugs (NSAIDs). Ibuprofen is a BCS class II drug with less solubility and high permeability [14]. Use of solid dispersion technique can enhance the solubility and dissolution rate and result in increasing the drug absorption of several BCS class II drugs [15-17]. The promising outcome of solid dispersion in enhancement of solubility and dissolution rate of poorly soluble drugs can be attributed to different aspects, such as crystalline to amorphous structure, improvement of local solubility and wettability for poorly soluble drugs in solid dispersion matrix and formation of metastable form of drug with increased solubility and dissolution rate in the presence of carrier $[18,19]$. In present work, an attempt has been made to develop controlled release matrix tablets of solid dispersed ibuprofen. A combination of swellable hydrophilic polymer and the nonswellable hydrophobic polymer was used to control the drug release from tablet matrix.

\section{MATERIALS AND METHODS}

\section{Materials}

Ibuprofen was received as a gift sample from Aurobindo Pharma Ltd., Hyderabad, India. Carbopol 934, Magnesium stearate and talc were commercially procured from Loba Chemie Pvt. Ltd., India. PEG 6000 was procured from Merck. Ethyl cellulose and lactose were purchased from SD Fine Chemicals. All the chemicals used were of analytical grade.

\section{Methods}

\section{Fourier transform infrared spectroscopy}

Drug-excipient interaction plays a vital role in the stability of drug from the formulation. Fourier transmitted infrared (FTIR) spectroscopy has been used to study the physical and chemical interactions between drugs and excipients. FT-IR spectra were recorded with FT-IR spectrometer (IRAffinity-1S, Shimadzu, Japan). Each sample was powdered and mixed with $\mathrm{KBr}$ (Uvasol, Merck, and KgaA, Germany). Pellets were prepared by using hydraulic press with a pressure of $100 \mathrm{Kg} / \mathrm{cm}^{2}$ for $15 \mathrm{~min}$. The pellets were then scanned from 4000 to $400 \mathrm{~cm}^{-1}$ with a mirror speed of $2 \mathrm{~mm} / \mathrm{sec}$. 
Drug-excipient compatibility study was carried out by the FT-IR analysis of pure drug ibuprofen, and the formulation containing ibuprofen and polymers [20].

\section{Preparation of solid dispersion of ibuprofen}

Solid dispersion of ibuprofen was prepared by melting-solvent method. Accurately weighed quantity of drug was taken in a clean and dry glass mortar and triturate well to a fine powder. Add sufficient quantity of methanol to above powder and triturate to get a uniform dispersion. Required amount of PEG 6000 was taken in a glass container and melted in a water bath at $60 \mathrm{C}[21,22]$. Then the ibuprofen-methanol solution was added to the molten mass of PEG 6000 and mixed uniformly for $5 \mathrm{~min}$. Then the mixture was placed on ice bath for rapid cooling until it solidified. The hardened mass was powdered in a mortar and then sieved through sieve no 60 . Then it was stored in an airtight glass vial at room temperature $[23,24]$.

\section{Preparation of controlled release matrix tablets of solid dispersed ibuprofen}

Six different formulations of ibuprofen were prepared by varying the polymer concentrations. All the ingredients, in which the drug, carbopol, ethyl cellulose, anhydrous lactose, talc, and magnesium stearate were weighed individually and sifted manually through mesh \# 40 separately. Thereafter, drug, ethyl cellulose, carbopoland lactose were mixed uniformly. Talc and magnesium stearate were finally added as lubricant and then mixed for further $5 \mathrm{~min}$. The weight of the tablet was determined as $500 \mathrm{mg}$ and the tablets were compressed (Rimek press) using a punch and die set to produce round shaped tablets with $3.35 \mathrm{~mm}$ thickness dimensions. Formulations F2 to F6 were also prepared by direct compression method but instead of pure ibuprofen, an equivalent weight of solid dispersed ibuprofen was used. Combinations of hydrophobic and hydrophilic polymers were used in a different concentration in order to achieve a controlled release of ibuprofen [25].

Table 1: Formulation of ibuprofen solid dispersed matrix tablets

\begin{tabular}{|c|c|c|c|c|c|c|}
\hline Ingredients (mg) & F1 & F2 & F3 & F4 & F5 & F6 \\
\hline Ibuprofen or solid dispersed ibuprofen equivalent to & 100 & 100 & 100 & 100 & 100 & 100 \\
\hline PEG 6000 & - & 100 & 150 & 200 & 250 & 300 \\
\hline Carbopol & 15 & 20 & 25 & 30 & 35 & 40 \\
\hline Ethyl Cellulose & 35 & 30 & 25 & 20 & 15 & 10 \\
\hline Lactose & 330 & 230 & 180 & 130 & 80 & 30 \\
\hline Talc & 10 & 10 & 10 & 10 & 10 & 10 \\
\hline Magnesium Stearate & 10 & 10 & 10 & 10 & 10 & 10 \\
\hline
\end{tabular}

\section{Evaluation of pre-compression parameters for powder blend}

All the pre-compression parameters such as bulk density, tapped density, angle of repose, Carr's index, Hausner's ratio were measured by following standard procedure [26].

\section{Evaluation of post-compression parameters of ibuprofen solid dispersed tablets}

\section{Tablet thickness}

Five tablets from each formulation were selected randomly and used for thickness test. Thickness of the prepared solid dispersed tablets was measured in mm by using Vernier calliper (Acculab, Ambala, India) [27].

\section{Hardness test}

Randomly selected five tablets were taken for hardness test which was subjected to "Monsanto" hardness tester by fitting them between the spindle and anvil through their diameter. The pressure was gradually increased then by turning the knurled knob until the tablet breaks. The force $(\mathrm{Kg})$ required to break the tablet is noted from the scale [27].

\section{Friability test}

The friability of tablets was determined by "Roche" friabilator. 10 tablets were weighted and placed in a plastic chamber of friabilator and allowed to rotate 100 revolutions at $25 \mathrm{rpm}$ for $4 \mathrm{~min}$. Then the tablets were removed, de-dusted and reweighed. The percentage friability was calculated as per formula [28].

$$
\% \text { Friability }=\frac{\text { Initial weight }- \text { Final weight }}{\text { Initial weight }} \times 100
$$

\section{Weight variation test}

Average weights of randomly selected twenty tablets were determined by weighing them individually. Individual weights of the tablets were compared with the average weight. If more than two of the individual weights should deviate from the average weight by more than $7.5 \%$ deviation and none should deviate by more than twice the percentage [27].

\section{Determination of saturated solubility}

Amodified solubilitydetermination method was used to determine the solubility of pure ibuprofen and solid dispersed ibuprofen. Solubility study for all the samples along with pure ibuprofen was carried out in distilled water. Pure ibuprofen and solid dispersed ibuprofen were taken in excess quantity in a stopper conical flask containing $10 \mathrm{ml}$ of distilled water. Then the flasks were sealed and shaken on a rotary shaker for 24 h. The sample solutions were collected and then filtered through Whatmann filter paper. Then $1 \mathrm{ml}$ of filtered solution was taken and suitably diluted with the respective media before measuring the absorbances in UV-Visible spectrophotometer at $220 \mathrm{~nm}$. The solubility of all the samples was determined in triplicates and the mean value and standard deviation were noted [29].

\section{Drug content uniformity}

10 tablets were selected randomly and then weighed and powdered by using a glass mortar and pestle. Powder quantity equivalent to 50 mg was taken and dissolved in $100 \mathrm{ml}$ of $\mathrm{pH} 7.2$ phosphate buffer. From the above drug solution, $1 \mathrm{ml}$ was withdrawn and diluted with $9 \mathrm{ml}$ of ${ }_{\mathrm{PH}} \mathrm{H} .2$ phosphate buffer. The solution was then filtered using a Whatman filter paper [20]. The absorbance of the filtered drug solution was measured by using a UV-VIS spectrophotometer (Thermo Spectronic UV-1, USA) at $\lambda_{\max } 220 \mathrm{~nm}$ and the drug content was determined by the following equation-

$$
\% \text { Drug content }=\frac{\text { Actual } \text { ibuprofen content in weighed quantity of tablets }}{\text { Theoritical amount of ibuprof en present in taken tablets }} \times 100
$$

\section{Swelling study}

Swelling study was performed by placing an accurately weighed tablet in a petri dish containing $20 \mathrm{ml}$ of phosphate buffer $\mathrm{pH}$ 7.2. The tablets were withdrawn at the predetermined time interval and the excess amount of fluid was soaked by a tissue paper [30, 31]. Then the tablet was weighed and the percentage weight gain was calculated by following formula-

$$
\text { Swelling index }=\left[\frac{\mathrm{W}_{\mathrm{t}}-\mathrm{W}_{0}}{\mathrm{~W}_{0}}\right] \times 100
$$

Where, $\mathrm{W}_{\mathrm{t}}=$ Weight of tablet after time " $\mathrm{t}$ "

$\mathrm{W}_{\mathrm{o}}=$ Initial weight of the tablet.

\section{Scanning electron microscopy}

The swelled tablet sample was collected and after drying it was coated with metal by using an ion sputtering device. The coated sample was then mounted on SEM instrument and the morphology of the surface was examined by SEI detector [32]. 


\section{In vitro drug release studies}

Dissolution of the tablets was carried out on USP type II paddle type dissolution apparatus (Veego VDA-6D, Veego Instruments Cooperation, India). According to I. P. 7.2 phosphate buffer was selected as dissolution medium and the volume was maintained 900 $\mathrm{ml}$. The temperature of the medium was set at $37 \pm 0.5{ }^{\circ} \mathrm{C}$. The rotational speed of paddle was set at $50 \mathrm{rpm} .10 \mathrm{ml}$ of sample was withdrawn at predetermined interval up to $8 \mathrm{~h}$ and the same volume of fresh dissolution medium was replaced for maintaining sink condition. The withdrawn samples were filtered and analyzed by UV-VIS spectrophotometer (Thermo Spectronic UV-1, USA) at $\lambda_{\max }$ $220 \mathrm{~nm}$ using ${ }_{\mathrm{P}} \mathrm{H} 7.2$ phosphate buffer as a blank and the cumulative percentage of drug release was calculated [20].

\section{Release Kinetics}

In order to understand the mechanism and kinetics of drug release, the result of the in vitro drug release study of formulated tablets were fitted with various kinetic equations, such as zero-order (percentage release versus time), first-order (log percentage of cumulative drug remaining versus time), Higuchi's model (percentage drug release versus square root of time), KorsmeyerPeppas model (log cumulative amount versus log time). Correlation coefficient $\left(\mathrm{R}^{2}\right)$ values were calculated for the linear curves obtained by regression analysis of the above plots [33-35].

\section{Zero-order kinetics}

The zero order rate describes the systems where the drug release rate is independent of its concentration.

A zero order release would be predicted by the following equation,

$$
Q_{t}-Q_{0}=K_{0} t
$$

Where,

$Q_{t}=$ Amount of drug release dissolved in time ' $t$ '.

$\mathrm{Q}_{0}=$ Initial amount of drug concentration in solution.

$\mathrm{K}_{0}=$ Zero order rate constant.

When the data was plotted as cumulative \% drug release Vs time, if the plot is linear then data obeys zero order kinetics with slope equal to $\mathrm{K}_{0}$. This model represents an ideal release profile in order to achieve the prolonged pharmacological action.

\section{First order kinetics}

The first order describes the release from the system where release rate is concentration dependent.

A first order release would be predicted by the following equation

$$
\log Q_{t}=\log Q_{0}-\frac{K_{1} t}{2.303}
$$

Where,

$Q_{t}=$ Amount of drug released in time ' $t$ '.

$Q_{0}=$ Initial amount of drug concentration in solution.

$\mathrm{K}_{1} \mathrm{t}=$ First order rate constant

When data were plotted as log cumulative $\%$ drug remaining verses time yields a straight line indicating that the release follows first order kinetics. The constant Kcan be obtained multiplying slope values.

\section{Higuchi's model}

Higuchi described the release of drugs from the insoluble matrix as a square root of a time-dependent process based on Fickian diffusion.

The graph was plotted as $\%$ cumulative drug released Vs square root of time.

$$
Q=K t^{1 / 2}
$$

Where,

$\mathrm{K}=$ constant reflecting design variable system $\mathrm{t}=$ time in hours.

\section{Korsmeyer-peppas equation}

This model describes drug release from a polymeric system. To find out the mechanism of drug release, an initial $60 \%$ drug release data were fitted in the Korsmeyer-Peppas model.

To evaluate the mechanism of drug release, it was further plotted in Peppas equation as log cumulative \% of drug released Vs time.

$$
\begin{gathered}
M_{t} / M_{\alpha}=K t^{n} \\
\log M_{t} / M_{\alpha}=\log K+n \log t
\end{gathered}
$$

Where,

$\mathrm{M}_{\mathrm{t}} / \mathrm{M}_{\alpha}=$ fraction of drug released at time $\mathrm{t}$

$\mathrm{t}=$ Release time

$\mathrm{K}=$ Kinetic constant (incorporating structural and geometric characteristics of preparation)

$\mathrm{n}=$ Diffusional exponent indicative of the mechanism drug

This model is used to analyze the release of pharmaceutical polymeric dosage forms depending on ' $n$ ' value when the release mechanism is not known or more than one type of release phenomenon was involved. $\mathrm{n} \leq 0.43$ symbolize Fickian release, $0.43<\mathrm{n}<0.85$ symbolize non-Fickian release, and $\mathrm{n} \geq 0.85$ indicates a case II transport.

\section{Hixson-crowell}

The Hixson-Crowell model describes the release from systems where there is a change in surface area and diameter of particles or tablets.

$$
Q_{t}^{1 / 3}-Q_{t}^{1 / 3}=K_{H C t}
$$

Where,

$Q_{t}=$ remaining amount of drug in the dosage form at time $t$,

$\mathrm{Q}_{0}=$ initial amount of the drug in the tablet

$\mathrm{K}_{\mathrm{HC}}=$ rate constant for Hixson-Crowell rate equation

\section{RESULTS AND DISCUSSION}

\section{Fourier transform infrared spectroscopy (FT-IR)}

FTIR spectrum of ibuprofen and formulation was shown in Fig.1. FTIR spectrum of ibuprofen shows the peak at $2955.47 \mathrm{~cm}^{-1}$ for C$\mathrm{H}$ stretching of alkane which is observed in the formulation at $2956.25 \mathrm{~cm}^{-1}$. Peaks for $\mathrm{C}=0$ stretching for carboxylic acid shows peak at $1722.58 \mathrm{~cm}^{-1}$ which can be observed in the formulation at $1718.82 \mathrm{~cm}^{-1}$. C-C stretching in the aromatic ring is observed for pure ibuprofen at $1418.10 \mathrm{~cm}^{-1}$ which is observed in the formulation at $1437.72 \mathrm{~cm}^{-1}$. C-O stretching for carboxylic acid shows peak at $1183.03 \mathrm{~cm}^{-1}$ which is also present in the formulation at $1184.23 \mathrm{~cm}^{-1}$. $\mathrm{O}-\mathrm{H}$ bending for carboxylic acid is observed at $936.73 \mathrm{~cm}^{-1}$ which can be seen in the formulation at $932.47 \mathrm{~cm}^{-1}$. The characteristic peaks appeared in the FTIR spectrum of ibuprofen is observed in the formulation without any significant shifting of peaks which indicates the absence of any chemical or physical interaction during and after preparation.

\section{Post-compression parameters}

Post-compression parameters such as tablet thickness, hardness, friability, and weight variation tests were carried out for prepared ibuprofen solid dispersed tablets and the results were found within the specified limits (table 2).

\section{Saturated solubility}

The saturated solubility of ibuprofen and solid dispersed ibuprofen in distilled water was shown in table 3 . The result of solubility studies indicated that ibuprofen is having low aqueous solubility in room temperature. The saturation solubility of ibuprofen was found 
to increase in solid dispersed ibuprofen. An increase in the concentration of PEG 6000 in the physical mixture of solid dispersed ibuprofen increased the saturation solubility of ibuprofen. This phenomenon could be due to the enhanced wetting property of ibuprofen [36, 37].

\section{Drug content}

The average drug content was calculated for each formulation. The drug content for prepared solid dispersed formulation was found to be within the range of $98.68 \pm 0.71 \%$ to $99.38 \pm 0.46 \%$ (table 2 ).

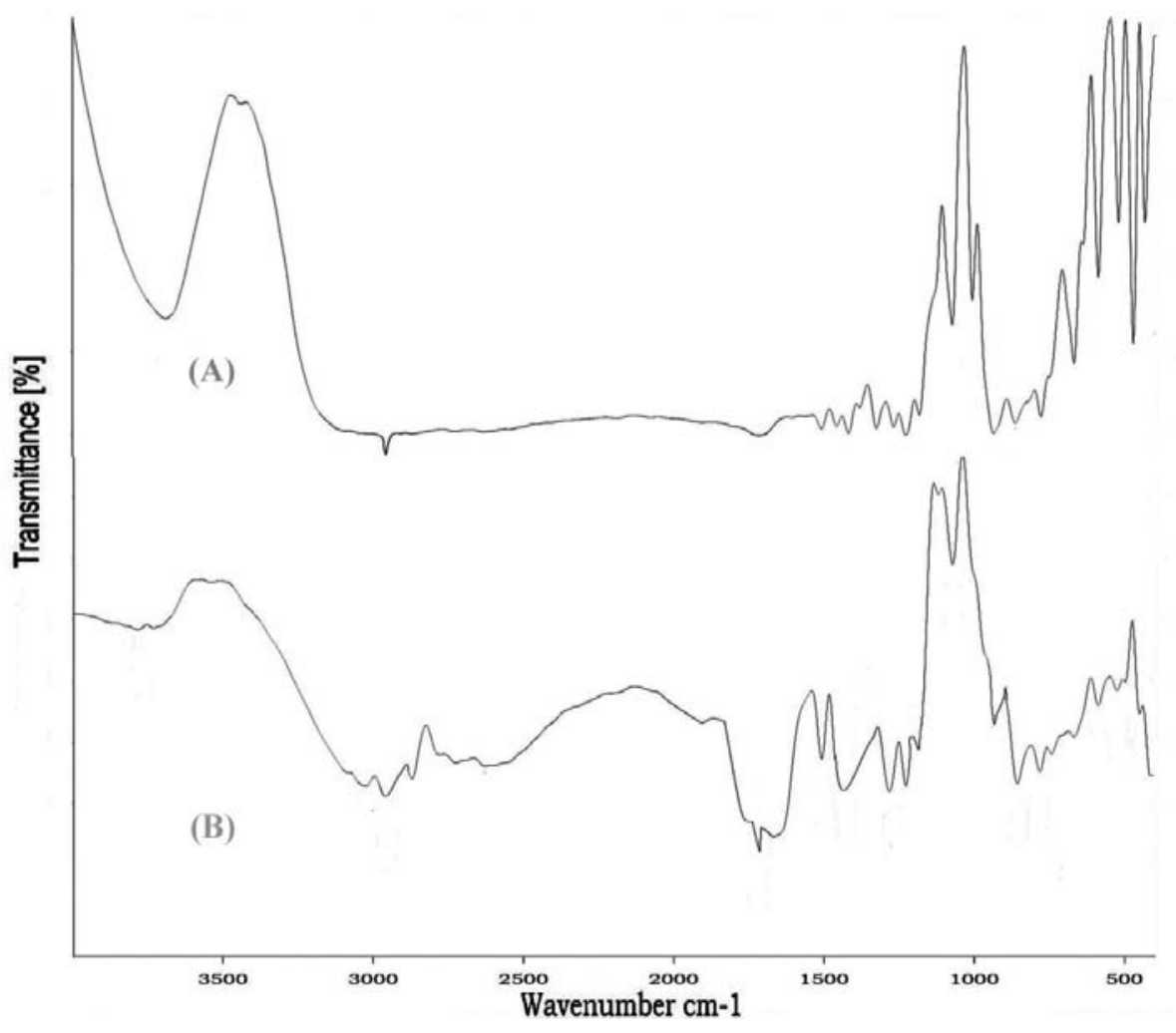

Fig. 1: FT-IR spectrum of-(A)-pure ibuprofen and (B)-formulation mixture

Table 2: Post-compression parameters of ibuprofen matrix tablets

\begin{tabular}{lllll}
\hline Formulation code & Thickness $^{*}(\mathbf{m m}) \pm$ SD & Weight variation test $^{* *}(\mathbf{\%}) \pm$ SD & Hardness $\left.^{*} \mathbf{( K g} / \mathbf{c m}^{3}\right) \pm$ SD & Friability $^{*}(\mathbf{\%}) \pm$ SD $(\boldsymbol{n}=\mathbf{1 0})$ \\
\hline F1 & $3.28 \pm 0.036$ & $497 \pm 1.80$ & $5.75 \pm 0.26$ & $0.61 \pm 0.07$ \\
F2 & $3.34 \pm 0.073$ & $499 \pm 1.63$ & $5.64 \pm 0.87$ & $0.52 \pm 0.04$ \\
F3 & $3.24 \pm 0.029$ & $498 \pm 1.14$ & $5.43 \pm 0.49$ & $0.47 \pm 0.05$ \\
F4 & $3.37 \pm 0.062$ & $497 \pm 1.38$ & $5.48 \pm 0.52$ & $0.54 \pm 0.03$ \\
F5 & $3.31 \pm 0.058$ & $497 \pm 1.72$ & $5.61 \pm 0.42$ & $0.51 \pm 0.05$ \\
F6 & $3.26 \pm 0.071$ & $499 \pm 1.47$ & $5.32 \pm 0.28$ & $0.42 \pm 0.06$ \\
\hline
\end{tabular}

${ }^{*} \mathrm{n}=10 ;{ }^{* *} \mathrm{n}=20 ;$ SD-Standard deviation

Table 3: Saturated solubility, percentage drug content and swelling index of prepared ibuprofen solid dispersed matrix tablets

\begin{tabular}{|c|c|c|c|}
\hline Formulation code & Saturated solubility $\mathrm{mg} / \mathrm{ml}$ & $\%$ Drug content mean \pm SD & Swelling index $\% \pm$ SD at SIF $\mathrm{pH}=7.2$ \\
\hline F1 & $1.82 \pm 0.07$ & $98.27 \pm 0.80$ & $90 \pm 5.43$ \\
\hline F2 & $3.27 \pm 0.24$ & $97.35 \pm 0.46$ & $99 \pm 4.28$ \\
\hline F3 & $3.41 \pm 0.18$ & $99.17 \pm 0.54$ & $113 \pm 8.76$ \\
\hline F4 & $3.53 \pm 0.27$ & $98.93 \pm 0.67$ & $118 \pm 7.42$ \\
\hline F5 & $3.59 \pm 0.34$ & $97.28 \pm 0.52$ & $126 \pm 5.87$ \\
\hline F6 & $3.86 \pm 0.39$ & $98.79 \pm 0.39$ & $137 \pm 6.41$ \\
\hline
\end{tabular}

$\mathrm{n}=3$; SD-Standard deviation

\section{Swelling study}

The swelling characteristics of solid dispersed matrix tablets of ibuprofen were studied in simulated intestinal fluid $(\mathrm{pH}$ 7.2). The swelling index for all the formulation was found within the limit of $90 \pm 5.43$ to $137 \pm 6.41$ as given in table 3 . From the above data it can be predicted that with the increase in the hydrophilic polymer in the formulation, the swelling index increased gradually. There was gradual disintegration found on the swollen tablet which created pores in tablet surface that has facilitated fluid penetration.

\section{Scanning electron microscope}

The surface morphology and porosity for the swelled tablet matrix was examined by scanning electron microscope. Fig. 2 displays the SEM image of F6 formulation. It is clearly observed from the image 
that the tablet surface is rough and porous in nature. The uneven swelling was achieved because of the unequal swelling of hydrophilic and hydrophobic polymers which created channels responsible for the inward flow of aqueous fluid and outward drug diffusion.

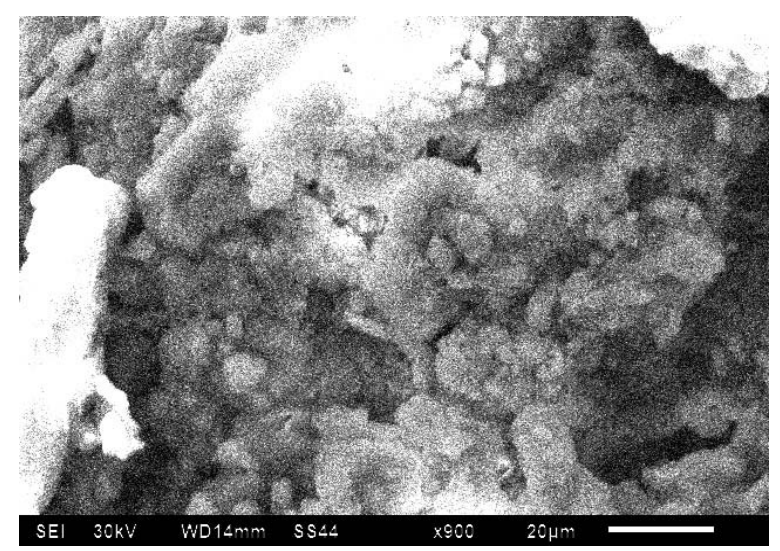

Fig. 2: SEM image of swollen tablet surface

\section{In vitro drug release study}

To understand the drug release profile from solid dispersed tablets of ibuprofen in vitro release study was performed in phosphate buffer at $\mathrm{pH} 7.2$ up to $8 \mathrm{~h}$. Then the cumulative percentage release was calculated. The cumulative percentage drug released Vs time plot is shown in fig. 3 for all formulations. The cumulative percent drug release after $8 \mathrm{~h}$ of dissolution was found to be within the range of $68.76 \pm 3.04$ to $95.33 \pm 2.34 \%$. The drug release was gradually increased with a higher concentration of carbopol which is a hydrophilic polymer. A higher amount of hydrophobic polymer tends to decrease the release of the drug. Due to the high viscosity of the polymers sustained release of ibuprofen was achieved [38].

\section{In vitro release kinetics}

The release kinetics of various formulations is described in table 4 . The average percentage release was fitted into different release models: Zero order, First order, Higuchi's plot, korsmeyer-peppas, and HixsonCrowell model. The correlation coefficients for formulations F1, F2, F3, F4, F5 and F6 are calculated from respective graphs. Based on the correlation values the release mechanism for F1, F2, F5, and F6 were found to follow korsmeyer-peppas kinetics for which value was found within the range of 0.290-0.33, indicating an anomalous behaviour (non-Fickian kinetics corresponding to coupled diffusion/polymer relaxation). F3 and F4 followed Hixson-Crowell model.

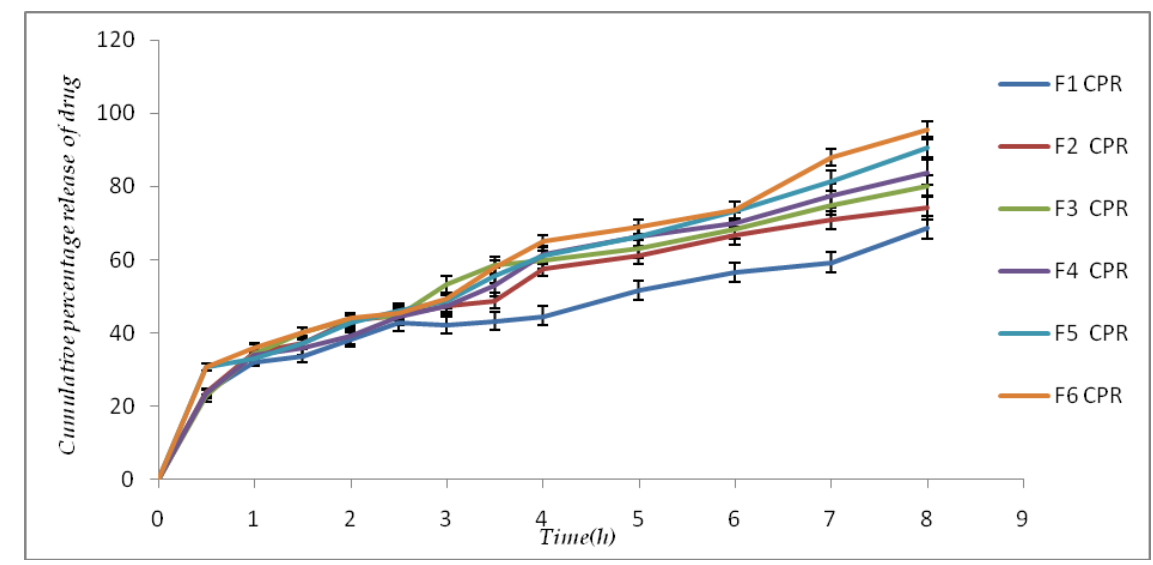

Fig. 3: Comparative C. P. R. of ibuprofen from solid dispersed matrix tablets (number of experiments, $n=3$; data given in mean \pm SD)

Table 4: Result of curve fitting of in vitro release of ibuprofen from solid dispersed matrix tablets

\begin{tabular}{|c|c|c|c|c|c|c|c|}
\hline \multirow{2}{*}{$\begin{array}{l}\text { Formulation } \\
\text { code }\end{array}$} & \multirow[t]{2}{*}{ Zero order $\mathbf{R}^{2}$} & \multirow[t]{2}{*}{ First order $\mathbf{R}^{2}$} & \multirow[t]{2}{*}{ Higuchi R $^{2}$} & \multicolumn{2}{|c|}{ Korsmeyer-peppas } & \multirow{2}{*}{$\begin{array}{l}\text { Hixson-crowell } \\
\mathbf{R}^{2}\end{array}$} & \multirow[t]{2}{*}{ Best fit model } \\
\hline & & & & $\mathbf{R}^{2}$ & $\mathbf{N}$ & & \\
\hline F1 & 1.50 & 0.922 & 0.927 & 0.935 & 0.251 & 0.925 & Korsmeyer-Peppas \\
\hline $\mathrm{F} 2$ & 0.98 & 0.975 & 0.970 & 0.967 & 0.290 & 0.965 & Korsmeyer-Peppas \\
\hline F3 & 0.80 & 0.960 & 0.921 & 0.965 & 0.313 & 0.004 & Hixson-Crowell \\
\hline $\mathrm{F} 4$ & 0.16 & 0.978 & 0.990 & 0.986 & 0.336 & 0.002 & Hixson-Crowell \\
\hline F5 & 0.20 & 0.918 & 0.978 & 0.965 & 0.308 & 0.961 & Korsmeyer-Peppas \\
\hline F6 & 0.11 & 0.857 & 0.968 & 0.959 & 0.311 & 0.729 & Korsmeyer-Peppas \\
\hline
\end{tabular}

\section{CONCLUSION}

The objective of the present research was to formulate solid dispersed tablets of ibuprofen to improve the dissolution rate and to investigate the effect of the combination of hydrophilic and hydrophobic polymers on drug release. The drug and excipient compatibility was checked by FT-IR. Solid dispersed tablets of ibuprofen were prepared by direct compression method with solid dispersed ibuprofen. Saturated solubility was examined in distilled water and it was found to increase for solid dispersed ibuprofen. The swelling study was also performed for all the formulation and swelling index was found satisfactory. After swelling, SEM image of the tablet surface confirmed the presence of numerous pores and swelled tablet surface. Then tablets were evaluated for in vitro drug release study which was carried out in phosphate buffer ${ }_{\mathrm{P}} \mathrm{H} 7.2$ up to
$8 \mathrm{~h}$ to give release range from $68.76 \pm 3.04 \%$ to $95.33 \pm 2.34 \%$. The dissolution data were subjected to different kinetics models. F1, F2, F5, F6 followed Korsmeyer-Peppas model and F3, F4 followed Hixson-Crowell. F6 was considered as best formulation based on drug release profile.

In conclusion, this system can be considered as one of the promising formulation technique for ibuprofen. The controlled release of the drug from polymer matrix can maximize the drug absorption and reduce the side effects. This technique can be used as a very useful means to increase the dissolution rate and reduction in dose.

\section{ACKNOWLEDGMENT}

The authors express their gratitude to the Department of Pharmaceutical Technology, Brainware University, Barasat, West 
Bengal and Koringa College of Pharmacy, Andhra Pradesh, India for encouraging and supporting to perform this work.

\section{AUTHORS CONTRIBUTIONS}

All the authors have contributed equally

\section{CONFLICT OF INTERESTS}

The authors declare no conflict of interest

\section{REFERENCES}

1. Martin A. Solubility and distribution phenomena, physical pharmacy and pharmaceutical sciences. Sixth ed. Lippincott Williams and Wilkins; 2011.

2. Sharma D, Soni M, Kumar S, Gupta GD. Solubility enhancementeminent role in poorly soluble drugs. Res J Pharm Tech 2009;2:220-4.

3. Patidar K, Soni M, Sharma KD, Jain KS. Solid dispersion: approaches, technology involved, unmet need and challenges. Drug Invention Today 2010;2:349-57.

4. Leuner C, Dressman J. Improving drug solubility for oral delivery using solid dispersions. Eur J Pharm Biopharm 2000;50:47-60.

5. Krishnaiah YSR. Pharmaceutical technologies for enhancing oral bioavailability of poorly soluble drugs. J Bioequiv Availab 2010;2:28-36.

6. Jain SK, Shukla M, Shrivastava V. Development and in vitro evaluation of ibuprofen mouth dissolving tablets using solid dispersion technique. Chem Pharm Bull 2010;58:1037-42.

7. Livshits A, Machtinger R, David LB, Spira M, Moshe Zahav A, Seidman DS. Ibuprofen and paracetamol for pain relief during a medical abortion: a double-blind randomized controlled study. Fertil Steril 2009;91:1877-80.

8. Laurel JMG, Benjamin DS. Cyclooxygenase-2 inhibitors: promise or peril? Mediators Inflamm 2002;11:275-86.

9. Akarca US. Gastrointestinal effects of selective and nonselective non-steroidal anti-inflammatory drugs. Curr Pharm Des 2005;11:1779-93.

10. Afshin Z, Sara A. Selective COX-2 inhibitors: a review of their structure-activity relationships. Iran J Pharm Res 2011;10:655-83.

11. Luong C, Miller A, Barnett J, Chow J, Ramesha C, Browner MF. Flexibility of the NSAID binding site in the structure of human cyclooxygenase-2. Nat Struct Biol 1996;3:927-33.

12. Meek IL, Laar MAFJVD, Vonkeman HE. Nonsteroidal antiinflammatory drugs: adverse effects and their prevention. Semin Arthritis Rheum 2010;39:294-312.

13. Yanbin H, Wei-Guo D. Fundamental aspects of solid dispersion technology for poorly soluble drugs. Acta Pharm Sin B 2014;4:18-25.

14. Tsume Y, Amidon GL, Takeuchi S. Dissolution effect of gastric and intestinal ${ }_{\mathrm{P}} \mathrm{H}$ for a BCS class II drug, pioglitazone: new in vitro dissolution system to predict in vivo dissolution. J Bioequiv Availab 2013;5:224-7.

15. Shobhit K, Satish KG. Pharmaceutical solid dispersion technology: a strategy to improve the dissolution of poorly water-soluble drugs. Recent Pat Drug Delivery Formul 2013;7:111-21.

16. Maulvi FA, Dalwadi SJ, Thakhar VT. Improvement of dissolution rate of aceclofenac by solid dispersion technique. Powder Technol 2011;207:47-54.

17. Waghmare A, Pore Y, Kuchekar B. Development and characterization of zaleplon solid dispersion systems: a technical note. AAPS PharmSciTech 2008;9:536-43.

18. Konno H, Handa T, Alonzo DE, Taylor LS. Effect of polymer type on the dissolution profile of amorphous solid dispersions containing felodipine. Eur J Pharm Biopharm 2008;70:493-9.
19. Verheyen S, Blaton N, Kinget R, Mooter VDG. Mechanism of increased dissolution of diazepam and temazepam from polyethylene glycol 6000 solid dispersions. Int J Pharm 2002;249:45-58.

20. Manna S, Jayasri K, Annapurna KR, Kanthal LK. Alginate-based gastro-retentive raft-forming tablets for enhanced bioavailability of tinidazole. Int J Appl Pharm 2017;9:16-21.

21. Ladan AN, Gurinder S, Gaurav S, Kimia FK. Solid dispersion: methods and polymers to increase the solubility of poorly soluble drugs. J Appl Pharm Sci 2012;2:170-5.

22. Sweta KS, Vijay S, Kamla P. Formulation and evaluation of taste masked rapid release tablets of sumatriptan succinate. Int J Pharm Pharm Sci 2012;4:168-74.

23. Sharma A, Jain CP. Preparation and characterization of solid dispersions of carvedilol with PVP K30. Res Pharm Sci 2010;5:49-56.

24. Jian XW, Mingshi Y, Frans VDB, Jari P, Thomas R, Jukka R. Influence of solvent evaporation rate and formulation factors on solid dispersion physical stability. Eur J Pharm Sci 2011;44:610-20.

25. Ahad HA, Anand BU, Nagesh K, Sai KD, Bindu MK. Fabrication of glimepiride datura stramonium leaves mucilage and polyvinyl pyrrolidone sustained release matrix tablets: in vitro evaluation. Kathmandu Univ J Sci Eng Tech 2012;8:63-72.

26. Dattatraya MS, Pooja SA, Parag DK, Avish DM. Formulation and in vitro evaluation of fast dissolving tablet of verapamil hydrochloride. Int J Pharm Pharm Sci 2018;10:93-9.

27. Aulton ME. Pharmaceutics, the science of dosage form design. Oxford: Churchill Livingstone; 2005.

28. Poreddy SR, Penjuri SCB, Damineni S, Vuppula S. Formulation and evaluation of colon targeted matrix tablet using natural tree gums. Int J Pharm Pharm Sci 2018;10:92-7.

29. Masum MAA, Florida S, Islam SMA, Reza MS. Enhancement of solubility and dissolution characteristics of ibuprofen by solid dispersion technique. Dhaka Univ J Pharm Sci 2012;11:1-6.

30. Al-Taani BM, Tashtoush BM. Effect of microenvironment $\mathrm{pH}$ of swellable and erodable buffered matrices on the release characteristics of diclofenac sodium. AAPS PharmSciTech 2003;4:1-6.

31. Colombo P. Swelling-controlled release in hydrogel matrices for oralroute. Adv Drug Delivery Rev 1993;11:37-57.

32. Ganesh S, Radhakrishnan M, Ravi M, Prasannakumar B, Kalyani J. In vitro evaluation of the effect of the combination of hydrophilic and hydrophobic polymers on controlled release zidovudine matrix tablets. Indian J Pharm Sci 2008;70:461-5.

33. Bourne DWA. Pharmacokinetics. In: Banker GS, Rhodes CT. ed. Mordern Pharmaceutics. Marcel Dekker, New York; 2002.

34. Higuchi T. Mechanism of sustained action medication. Theoritical analysis of the rate of release of solid drugs dispersed in solid matrices. J Pharm Sci 1963;52:1145-9.

35. Ritger PL, Peppas NA. A simple equation for description of solute release I. fickian and non-fickian release from nonswellable devices in the form of slabs, spheres, cylinders or discs. J Controlled Release 1987;5:23-36.

36. Zahra S, Azade T, Alireza H. Preparation and physicochemical characterization of meloxicam orally fast disintegration tablet using its solid dispersion. Braz J Pharm Sci 2017;53:1-9.

37. Gupta MM, Patel MG, Patel NS, Madhulika K. Enhancement of dissolution rate of ibuprofen by preparing solid dispersion using different methods. Int J Pharm Pharm Sci 2011;3:204-6.

38. Hadi MA, Lokeswara BV, Pal N. Formulation and evaluation of sustained release matrix tablets of glimepiride based on the combination of hydrophilic and hydrophobic polymers. J Appl Pharm Sci 2012;2:101-7. 